\title{
Stayhome Hashtag: Sentiment Analysis on Twitter During the Covid-19 Pandemic
}

\section{ESJ Social Sciences}

\section{Ugur Gunduz}

Prof.Dr., Istanbul University Faculty of

Communication, Department of Journalism, Turkey

Submitted: 16 November 2020

Accepted: 03 December 2020

Published: 31 December 2020

Corresponding author:

Ugur Gunduz

DOI: 10.19044/esj.2020.v16n34p62

(c) Copyright 2020 Gunduz U

Distributed under Creative Commons BY-NC-ND 4.0 OPEN ACCESS

\begin{abstract}
With developing technology today, social media has entered every area of our lives. Many people come together and share in social media platforms without time and space restrictions. Social media has been in our lives so much lately. It is an undeniable fact that global outbreaks, which constitute an important part of our lives, are also affected by these networks and that they exist in these networks and share the users. The purpose of making this hashtag analysis is to reveal the difference in discourse and language while analyzing twitter data, while doing this, to evaluate the effects of a global epidemic crisis on language, message and crisis management with social media data. Sentiment analysis of tweets, on the other hand, objectives to take a look at the contents of these messages, to degree the feelings and feelings conveyed. This form of analysis is typically completed through amassing textual content data, then investigating the "sentiment" conveyed. Within the scope of our study, one hundred thousand twitter messages posted with the \#stayhome hashtag between 23 May 2020 and 29 May 2020 were examined. The impact and reliability of social media in disaster management could be questioned by carrying out a content analysis based totally on the semantic analysis of the messages given on the Twitter posts with the phrases and frequencies used. Social media and Twitter content are increasingly more identified as treasured resources of public health signals concerning use in ailment surveillance and health disaster management.
\end{abstract}

\begin{tabular}{llr} 
Keywords: & \multicolumn{1}{c}{ Stayhome } & Hashtag \\
(\#Stayhome), Coronavirus, & Covid-19 \\
Pandemic, Hashtag Analysis, & Twitter
\end{tabular}


Analysis, Sentiment Analysis, Social

Networking

\section{Introduction}

The Coronavirus Disease 2019 (COVID-19) outbreak caught the whole world surprisingly offhand. This pandemic, there has been almost no one generation in the world before, is not like cholera or plague, which history will teach us from the world today. The fact that everywhere is accessible in the modern world is one of the factors that make it difficult to prevent the epidemic. The developed countries of the capitalist economy, on the other hand, are confused that this epidemic, which they do not take seriously enough, will threaten themselves. Consequently, it does not seem possible for capitalism to find a solution to the inner contradictions that it is currently experiencing. Since even the most ambitious predictions of how long the pandemic will last are expressed in years.

"It took time for the rest of the world to understand the extent of the danger that the virus, which first appeared in Wuhan, China in December 2019, will pose to public health. During the first two months of 2020, crosscountry movements and hence the expansion continued" (Chen, et al., 2020). "While the severity of the situation increased irrevocably during the lost time, it was until March 11, 2020, that the world understood that it had a common problem and that the World Health Organization declared the COVID-19 outbreak pandemic" (WHO, 2020a). "The approaches of leaders in the most developed countries of the world, such as the USA and the UK, that reject science and disregard public health, led the problem to the crisis stage and the epidemic to evolve into dramatic points in a short time in European countries such as Italy and France. It was announced the day of the announcement of the first case of pandemic and flights cancelled, border closure, measures began with the holiday of schools and universities. The government of the medical priority is very capital-driven consider their economic stimulus packages, citizens also stay at home 'proposed' brought about a process" (Tufan \& Kayaaslan, 2020).

These calls, which intensely increased in social media with slogans, especially \#stayhome, continued to be shared without thinking that they corresponded to an apolitical point. In this case, the purpose of the measure is to suggest that millions of workers who do not have the choice other than free leave or firing stay at home if they do not continue to work at the workplace. "Warning people who have to go to work by using public transport every day as "Public transport is at risk". Proposing "10 delicious movies that can be watched at home" to the white-collar, which depends on the speed of connection to the server" (WHO, 2020b). These examples reveal a clear classification that will not require vast analysis of capitalism. On the other 
hand, the conspiracy theories that have become widespread as a result of the radically increasing use of social media in the moments of crisis and the source of the virus provide important data to see how man escapes responsibility as the subject in the production of nature and space. For example, conspiracy theories such as COVID-19 is produced in laboratories in the United States, designed as a biological weapon to collapse the economy of China, tried such a way to eliminate the elderly within the scope of the reduction of the world population, or produced by China to monetize a vaccine fund that reaches wide audiences (Nie, 2020) in populist ways.

However, is the class equivalent of the relationship we have with nature or staying at home unknown in this world where everything is social, from the water we drink to the air we breathe? As long as it is known but not spoken out loud, it is easier to manipulate these truths. For this reason, it is important to discuss the natural and spatial contradictions underlying the class separations revealed by the coronavirus propaganda that it is equally affecting everybody as a pandemic case (Bjørkdahl \& Carlsen, 2019) and a universal problem, and seeking answers to the questions regarding the roles of social subjects in this process.

While sharing on Twitter under the tag \#stayhome, we click on the stream in an "accelerated way", the spirit of the 21 st century, and spread the content with another click. During this spread, we see that what is popular, interesting, fun and even ridiculous and wrong, not reliable and correct, is spreading rapidly, even equivalent to the geometric velocity of Covid-19. If we already know that the algorithm of all kinds of social media platforms, the network's architecture has placed us in certain echo rooms and filter balloons, then we can realize that our ability to encounter content is as limited as radically changing our lifestyle (Bucher, 2017).

Moreover, the main appeal of platform capitalism is that it allows the user to use individualized use and convergent content. In this case, the content we produce and consume will always remain within a certain information frame due to algorithms, individualization and convergence. Such algorithms determine that the installation information below, and we tried to follow the agenda of the label certain content flows, which appear in the new media ecosystem of the world there is a new phenomenon: The fog of information (Adelaja, Sayma, Walton, McLachlan, Boisanger \& Bartlett-Pestell, 2020).

When we look at Twitter, the virus is produced as a biological weapon, the vaccine will cause infertility in men, etc. Conspiracy theories go into circulation, or we see the contents in the form of social panic that "corona is encountered in x hospitals in city x". To prevent the spread of Covid-19, the basic measures- hygiene, social distance, etc. - instead of information transmitting, such content is in the flow with remarkable visuals (WHO, 2020c). A complete information fog...A lot of effort is required to get the right 
information from this fog. In the face of what we call information loading or information fog, we are dealing with selectivity in perception and cognition or screening-quick browsing (Dijk, 2006). Scanning or quick browsing leads to sacrificing quality and turning towards superficial reading to reach more quantity in the face of the abundance of flow. Superficial reading means looking at the title and entry of a clicked link, at best, the end of the content is lost, reading the result.

\section{The Role of Social Media in Global Pandemic Crises}

Information sharing is a human response to disaster events. Social media structures enable people to come collectively and share facts on exceptional scales and in new ways. In only a few years, these systems have become a part of the important infrastructure of crisis intervention. As a matter of fact, social networks today have become a place where people come together to understand developments and to address their psychological and social effects.

"The internet has become one of the most important resources for the general population when searching for healthcare information. However, the information available is not always suitable for all readers because of its difficult readability. We sought to assess the readability of online information regarding the novel coronavirus disease 2019 (COVID-19) and establish whether they follow the patient educational information reading level recommendations" (Szmuda, Özdemir, Ali, Singh, Syed \& Słoniewski, 2020).

While people around the world are struggling with the effects of the COVID-19 outbreak, they are also trying to deal with a parallel infusion. The concept of infodemia, first implemented by the WHO, expresses the dynamics of our modern knowledge field where reliable information is difficult to distinguish from the overwhelming competition and in some cases contradictory sounds (WHO, 2020b). Indeed, there are countless false rumours about COVID-19, purposeful misinformation, and baseless conspiracy theories in both online and offline channels. In social networks and WhatsApp groups, this information has spread faster than the virus and continues to spread.

The conspiracies, identified by the World Health Organization as "infodemics", extend to linking the pandemic and immigrants, as well as claiming that the virus has spread by $5 \mathrm{G}$ network towers. Doctors around the world, including Europe, have asked social media tech giants to speed up their fight against disinformation in the middle of the coronavirus pandemic. Global health experts said in an open letter to Facebook, Twitter, and Google that they continue to face viral misinformation on socially threatening social media around the world. (DGC, 2020). 
"Twitter is a popular source of health information" (Love, Himelboim, Holton, \& Stewart, 2013, p.568). "During public health outbreaks, analyzing social media text can provide first responders with useful insights about public fears and trending topics" (Lachlan, Spence, \& Lin 2014; Yoon, Elhadad \& Bakken, 2013, p.556). "Government and public netizens coexist in a social network. When an emergency occurs, online rumours spread quickly and take diverse forms, thereby affecting decision making and information dissemination via official media" (McGregor, 2019, p.1071). Tang, Chow, Breen, and Prigerson (2019) argue that "to understand the relationship between individuals and the media during the spread of online rumours, it is necessary to construct a simulation model of how public opinion develops".

They stated that fake claims and conspiracy theories continue to be shared on platforms such as Facebook, Twitter, YouTube... and also the promotion of fake treatments scares people from vaccines and effective treatments. During this period, Facebook said it removed hundreds of thousands of harmful false information about COVID-19 and applied warning labels from independent information controllers to 40 million messages only in March. In the statement made by Facebook; "Our practices include distributing accurate health information. So far, we have directed more than two billion people to resources transferred from health officials through our COVID-19 Information Center. Thus, over 350 million people clicked on these contents to learn" expressions were included (Jones, 2020).

Also, Facebook has carried out a series of actions that prohibit advertisements trying to exploit the crisis (for example, using false information to sell medicinal products), directing users to authorized information about COVID-19. Twitter, which has updated its security policy and expanded the definition of harm, has stated that it will prohibit tweets that may make people at higher risk of transmitting COVID-19. The platform also implemented new procedures to validate and promote the content of "authoritative voices" in the coronavirus. Of course, self-regulation is very important in this period and it is very important in this process to take into account and share the statements made by the state institutions and organizations.

\section{Methods}

Being a keystone in all forms of social media communication, interactivity between influencers and followers is central to describing influencers' communicative strategies. Interactivity on twitter takes different forms/actions, including tweet favouriting, retweeting and sentiment analysis of tweet texts.

Regarding the circulate of data, we can talk about four main applications: Transferring the facts to the public, exchange of information 
between verified account and followers, obtaining followers. Informative posts and networking may lead to qualitative records in order to help understand the crisis. They consist of the messages of the health authority, the crisis-related causes, precautions to be taken and accurate information about the epidemic, such as the number of patients and deaths.

Twitter, one of the largest social media platforms, is a micro blog-type social networking site where thoughts and expressions are expressed in short sentences. It is a social networking platform where people can write texts up to 140 characters and up to 280 characters. Twitter has more than 330 million users worldwide. Millions of posts are shared on Twitter in minutes. Also, the use of tags (\#hashtag) has been launched on Twitter for the first time in the world and all social networks have started to use this feature in the process (Karabulut \& Küçüksille, 2018). Tags allow users to categorize their views on a particular framework. Users can share on labels according to their interests, so communities with the same or similar interests can come together, brands can reach their potential customers, and non-governmental organizations can interact with their target audience. At this point, labels are used actively and continuously all over the world.

Within the scope of our study, a hundred thousand twitter messages posted with the \#stayhome between 23 May 2020 and 29 May 2020 were examined. The impact and reliability of social media in disaster management could be questioned by carrying out a content analysis based totally on the semantic analysis of the messages given on the Twitter posts with the phrases and frequencies used. The general purpose of this research is to interpret the agenda and measure the emotional state of the users based on the \#stayhome, which is used extensively on coronavirus days on Twitter.

\section{Results}

Hashtags help people express their feelings and funny stories during the pandemic. Social networking has been a lifeline for millions in recent days, when a growing number of people around the world are encouraged to isolate themselves at home. Microblogging sites such as Twitter, have now been one of the easiest and most convenient ways of getting information and alerts from the government. It has become a platform for people to send or receive color humor, reposts, and analysis on the world as it improves. Some have tweeted their experience of self-isolation, in hopes of encouraging those who could easily descend into tiny apartment-induced isolation. Stayhome hashtag is one of the most widely used hashtags in the time of coronavirus pandemic, which usually contains more extreme warnings from people encouraging their mutual social media friends to stay home and self-isolate. It's natural to expect more public health officials and the like to use the same one. 
In this study, tweets for \#stayhome on Twitter were used. In the evaluation made with sentiment analysis, which is one of the text mining tools, the labels determined in the study are listed according to their emotional values. Within the scope of the evaluation, besides the emotions contained in the tweets, the results were reached such as how many people read the posts, what languages were shared, those who reached the highest number of users and which words and concepts were shared. Workbench social media monitoring and analysis tool was used to analyze the posts labelled \#stayhome.

"Workbench uses the Vader Sentiment Analysis. VADER (Valence Aware Dictionary and Sentiment Reasoner) is a lexicon and rule-based sentiment analysis tool that is specifically attuned to sentiments expressed in social media and works well on texts from other domains" (Conti, 2020).

Table 1. \#stayhome analysis on Twitter

\begin{tabular}{cc}
\hline Created_at & Average Sentiment \\
\hline 23 May 2020 Saturday & 0.2454181013252012 \\
24 May 2020 Sunday & 0.29429274087111934 \\
25 May 2020 Monday & 0.29665897452373163 \\
26 May 2020 Tuesday & 0.2293314227523995 \\
27 May 2020 Wednesday & 0.2693426535087722 \\
28 May 2020 Thursday & 0.2918706914344691 \\
29 May 2020 Friday & 0.24634097363083182 \\
\hline
\end{tabular}

The results of the average sentiment analysis are listed in table 1 with the \#stayhome and the most used tags and keywords are identified in the tweets. "Hashtags are helping people share thoughts and funny experiences through the pandemic. Social media has emerged as a lifeline to many in recent pandemic days, as more and more people around the arena are encouraged to isolate themselves at home. As such, social media platforms have also emerged as one of the fastest and best approaches to acquire facts and updates from the authorities. It's also grown to be an area for people to give and obtain light-hearted banter, memes and statement on the sector as it changes. Many had been tweeting their stories in self-isolation, in the hopes of inspiring others 
who may be quickly descending into small apartment-induced boredom" (Stewart, 2020).

Figure 1. \#stayhome hashtag sentiment analysis on Twitter (23-29 May 2020)

\#stayhome Hashtag Sentiment Analysis on Twitter

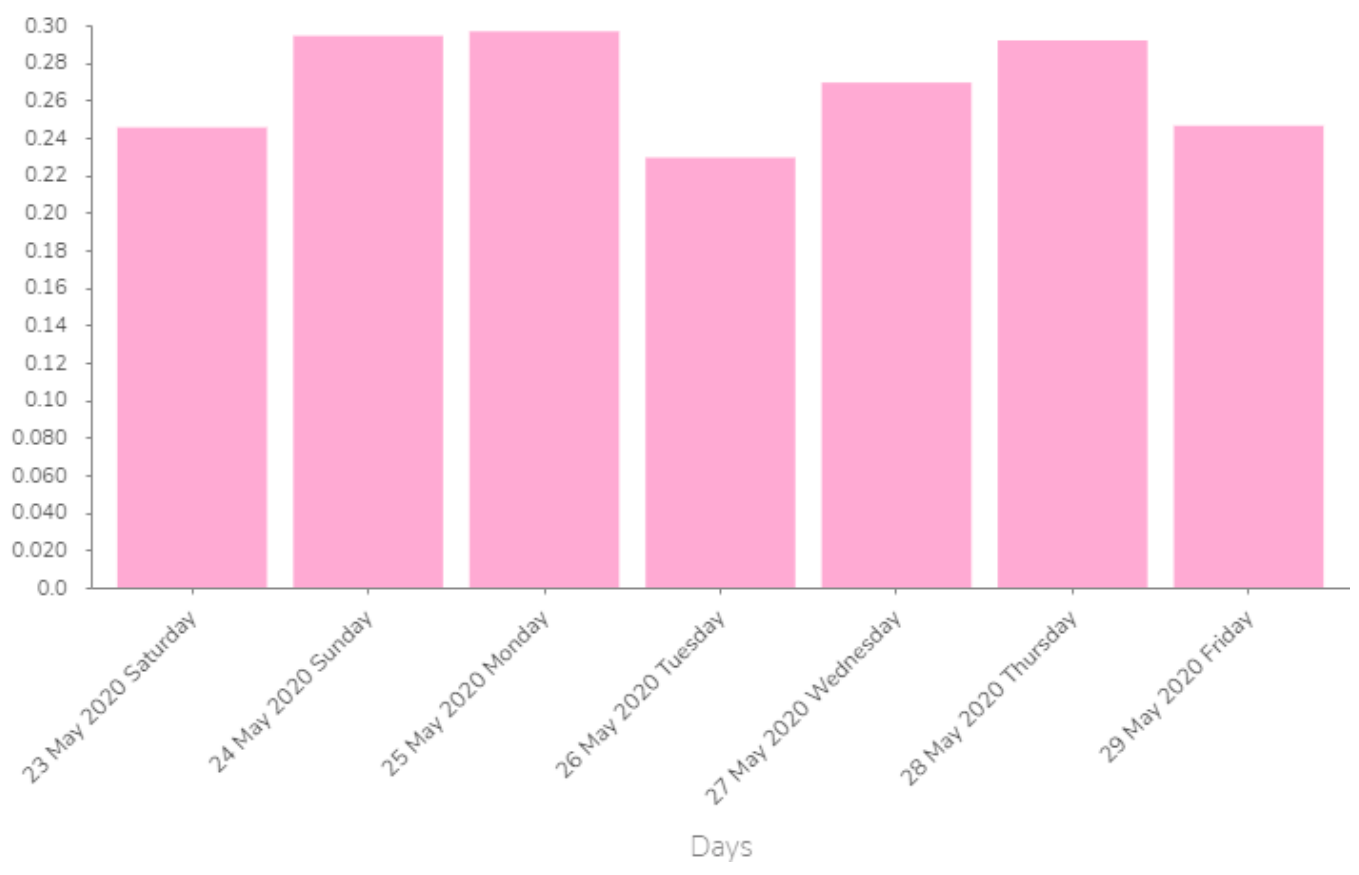

As seen in figure 1, \#stayhome hashtag has a positive mood in the average sentiment analysis by days. "\#StayHome generally includes more stern instructions from people urging their fellow social media users to stay home and self-isolate. Expect to see extra health authorities and the likes using this one. You may additionally see the call of a rustic tagged on to the quit of this one, as Twitter users target precise areas" (Stewart, 2020).

"Sentiment analysis is used in opinion mining, business analytics and reputation monitoring. It helps businesses understand how happy or dissatisfied the customer is with a particular service or product by analyzing their emotional tone from the product reviews they post, the online recommendations they make, their survey responses and other forms of social media" (Conti, 2020). 


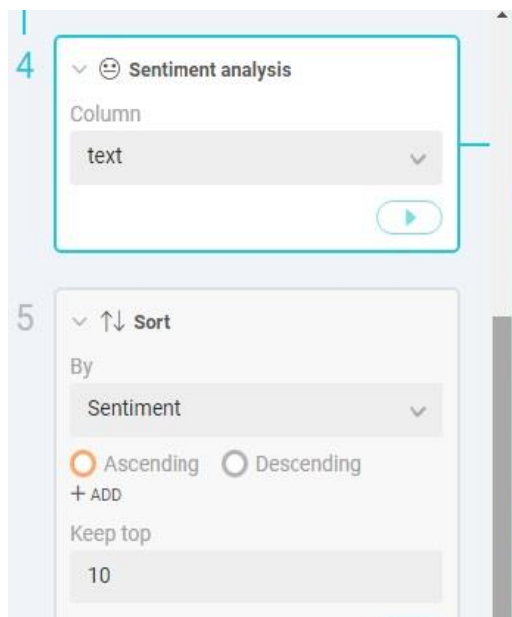

\begin{tabular}{|c|c|c|c|c|c|}
\hline & $\begin{array}{l}\text { RoWs } \\
100,000\end{array}$ & $\begin{array}{c}\text { COLUMNS } \\
12\end{array}$ & No rows selected & & \\
\hline & $\begin{array}{l}\text { Sentiment } \\
\text { number }\end{array}$ & & $\begin{array}{l}\text { B } \\
\text { screen_name } \\
\text { text }\end{array}$ & $\begin{array}{l}\text { created_at } \\
\text { date } \& \text { time }\end{array}$ & $\begin{array}{l}\text { text } \\
\text { text }\end{array}$ \\
\hline 999ea & & 0 & hiro_3861 & 2020-05-23T14:20:51Z & RT @nissay_official: \#つ... \\
\hline 99984 & & 0 & $12 \mathrm{chz}$ & 2020-05-23T14:20:51Z & RT@y_matwee: 『モノの... \\
\hline 99995 & & 0.0323 & teppen_meimei & 2020-05-23T14:20:51Z & RT @ONEOKROCK_japan:... \\
\hline 99996 & & 0 & jvft5ifbWLsovA: & 2020-05-23T14:20:50Z & RT@moncafeofficial: / 」.... \\
\hline 99997 & & 0 & $15 f 59703 d c c 4429$ & $2020-05-23 T 14: 20: 50 Z$ & RT@sora000207:ベイマ... \\
\hline 99969 & & 0.7177 & ayuwindari06 & 2020-05-23T14:20:50Z & Bukan mau memutus tali ... \\
\hline 99999 & & 0 & iQxGCU2P4Tv5 sy & $2020-05-23 T 14: 20: 50 Z$ & RT @sankakumadoeiga: ... \\
\hline 99990 & & 0 & SudarshanPanto1 & 2020-05-23T14:20:50Z & RT @COVIDNewsByMIB:... \\
\hline
\end{tabular}

Figure 2. "VADER (Valence Aware Dictionary and sEntiment Reasoner) is a lexicon and rule-based sentiment analysis tool that is specifically attuned to sentiments expressed in social media" (Hutto \& Gilbert, 2014).

"This module takes a text column has an input to create a new sentiment, displaying an index between -1 and 1 for each value in the selected column.

- 1 Means 'Very positive'

- 0 means 'Neutral'

- $\quad-1$ Means 'Very negative'

It is also useful for researchers who would like to set standardized thresholds for classifying sentences as either positive, neutral, or negative. Typical threshold values are" (Hutto \& Gilbert, 2014):

"Positive sentiment: compound score $>=0.05$

Neutral sentiment: (compound score > -0.05) and (compound score < 0.05 )

Negative sentiment: compound score $<=-0.05$ 


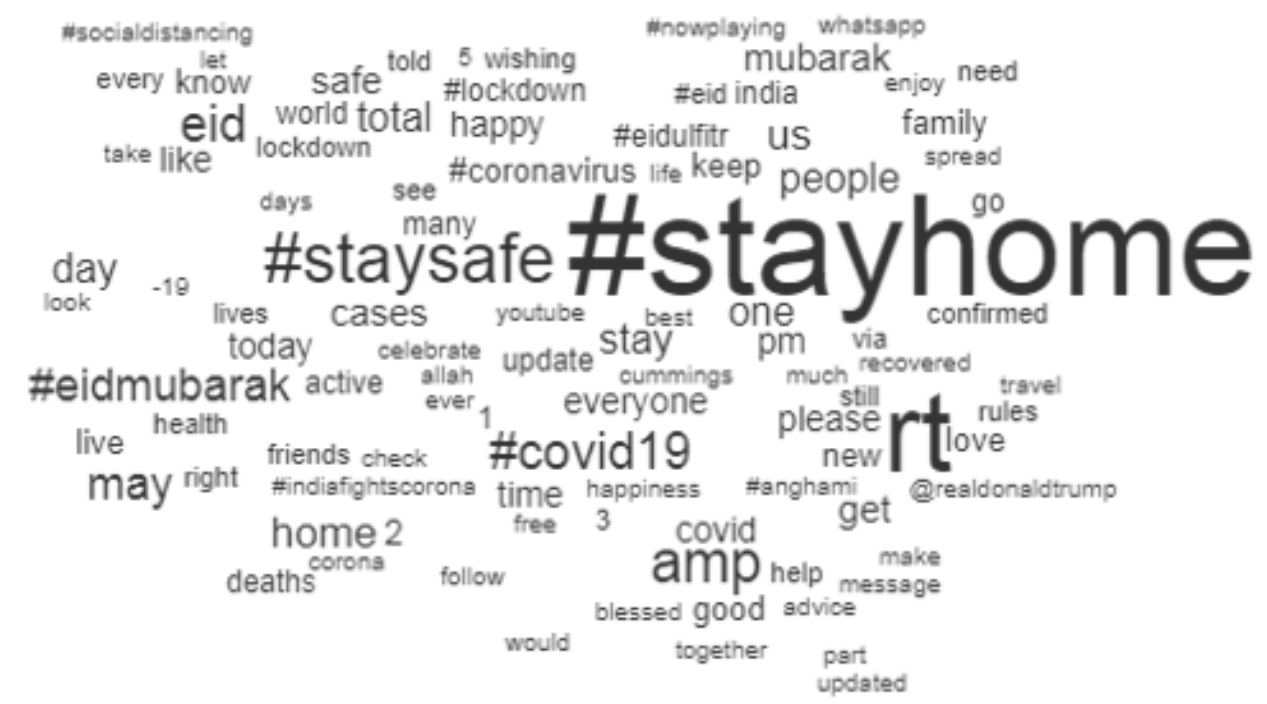

Figure 3. Word cloud depicting the most commonplace monograms taking place in tweets pertaining to coronavirus outbreak

As shown in the figure 3 (word cloud results), the coronavirus outbreak seemed to focus on Twitter's special aspects of the disaster. The word cloud results using one of a kind words of "covid19" and "coronavirus" lower returned a remarkable set of frequently related words during the pandemic.

Table 2. Top 10 most frequently words in average sentiment values positive

\begin{tabular}{cc}
\hline Weight & Words \\
\hline 6 & full \\
6 & joy \\
6 & one \\
5 & Eid \\
3 & Allah \\
3 & Amin \\
3 & blessed \\
3 & blessings \\
3 & bring \\
3 & eid
\end{tabular}


Table 3. Top 10 most frequently words in average sentiment values negative

\begin{tabular}{cc}
\hline Weight & Words \\
\hline 12 & Wrong \\
8 & War \\
6 & illness \\
6 & mental \\
6 & severe \\
6 & StayHome \\
4 & Americans \\
4 & homeless \\
4 & killed \\
4 & percent \\
\hline
\end{tabular}

Table 4. Top $10+$ (positive) sentiment twitter postings

\begin{tabular}{|c|c|c|c|}
\hline Sentiment & Screen_name & Created_at & Text \\
\hline 0.9911 & badarshamim & $\begin{array}{c}24.05 .2020 \\
17: 52\end{array}$ & $\begin{array}{l}\text { RT @ BramptonMasjid: Eid Mubarak! Wishing every one a warm, } \\
\text { happy \& full of joy Eid. May the blessings of Allah bring love, } \\
\text { joy, good health, wealth, \& happiness, and make it a very blessed } \\
\text { one \& full of peace for everyone. Amin! \#eid \#EidMubarak } \\
\text { \#EidUlFitr \#StayHome \#staysafe \#onpoli \#cdnpoli } \\
\text { https://t.co/TdETdAqC9d }\end{array}$ \\
\hline 0.9911 & AmyaSpringvaley & $\begin{array}{c}25.05 .2020 \\
09: 18\end{array}$ & $\begin{array}{l}\text { RT @ BramptonMasjid: Eid Mubarak! Wishing every one a warm, } \\
\text { happy \& full of joy Eid. May the blessings of Allah bring love, } \\
\text { joy, good health, wealth, \& happiness, and make it a very blessed } \\
\text { one \& full of peace for everyone. Amin! \#eid \#EidMubarak } \\
\text { \#EidUlFitr \#StayHome \#staysafe \#onpoli \#cdnpoli } \\
\text { https://t.co/TdETdAqC9d }\end{array}$ \\
\hline 0.9911 & BramptonMasjid & $\begin{array}{c}24.05 .2020 \\
17: 44\end{array}$ & $\begin{array}{l}\text { Eid Mubarak! Wishing every one a warm, happy \& full of joy Eid. } \\
\text { May the blessings of Allah bring love, joy, good health, wealth, \& } \\
\text { happiness, and make it a very blessed one \& full of peace for } \\
\text { everyone. Amin! \#eid \#EidMubarak \#EidUlFitr \#StayHome } \\
\text { \#staysafe \#onpoli \#cdnpoli https://t.co/TdETdAqC9d }\end{array}$ \\
\hline 0.9911 & versace_tai & $\begin{array}{c}24.05 .2020 \\
19: 22\end{array}$ & $\begin{array}{l}\text { RT @ BramptonMasjid: Eid Mubarak! Wishing every one a warm, } \\
\text { happy \& full of joy Eid. May the blessings of Allah bring love, } \\
\text { joy, good health, wealth, \& happiness, and make it a very blessed } \\
\text { one \& full of peace for everyone. Amin! } \\
\text { \#eid \#EidMubarak \#EidUlFitr \#StayHome \#staysafe \#onpoli } \\
\text { \#cdnpoli https://t.co/TdETdAqC9d }\end{array}$ \\
\hline 0.9911 & Promisedmessia3 & $\begin{array}{c}24.05 .2020 \\
23: 30\end{array}$ & $\begin{array}{l}\text { RT @ BramptonMasjid: Eid Mubarak! Wishing every one a warm, } \\
\text { happy \& full of joy Eid. May the blessings of Allah bring love, } \\
\text { joy, good health, wealth, \& happiness, and make it a very blessed } \\
\text { one \& full of peace for everyone. Amin! \#eid \#EidMubarak } \\
\text { \#EidUlFitr \#StayHome \#staysafe \#onpoli \#cdnpoli } \\
\text { https://t.co/TdETdAqC9d }\end{array}$ \\
\hline 0.9911 & Atifa1524 & $\begin{array}{c}24.05 .2020 \\
18: 22\end{array}$ & $\begin{array}{l}\text { RT @ BramptonMasjid: Eid Mubarak! Wishing every one a warm, } \\
\text { happy \& full of joy Eid. May the blessings of Allah bring love, } \\
\text { joy, good health, wealth, \& happiness, and make it a very blessed } \\
\text { one \& full of peace for everyone. Amin! \#eid \#EidMubarak } \\
\text { \#EidUlFitr \#StayHome \#staysafe \#onpoli \#cdnpoli } \\
\text { https://t.co/TdETdAqC9d }\end{array}$ \\
\hline
\end{tabular}


$0.9911 \quad$ FdAffan

24.05.2020

0.9911 dxnyxl_27

0.9911 AhmadiyyaOttawa

24.05 .2020

11:52

0.9911 AmmarAhmadd
11:54

RT @FdAffan: Eid Mubarak! Wishing every one a warm, happy $\&$ full of joy Eid. May the blessings of Allah bring love, joy, good health, wealth,\& happiness, and make it a very blessed one \& full of peace for everyone. Amin! \#eid \#EidMubarak \#EidUlFitr \#StayHome \#staysafe \#onpoli \#cdnpoli https://t.co/mDewcl52My RT @ BramptonMasjid: Eid Mubarak! Wishing every one a warm, happy \& full of joy Eid. May the blessings of Allah bring love, 25.05.2020 joy, good health, wealth,\&happiness, and make it a very blessed 01:00 one \& full of peace for everyone. Amin! \#eid \#EidMubarak \#EidUlFitr \#StayHome \#staysafe \#onpoli \#cdnpoli https://t.co/TdETdAqC9d

RT @FdAffan: Eid Mubarak! Wishing every one a warm, happy $\&$ full of joy Eid. May the blessings of Allah bring love, joy, good health, wealth, \& happiness, and make it a very blessed one \& full of peace for everyone. Amin! \#eid \#EidMubarak \#EidUlFitr \#StayHome \#staysafe \#onpoli \#cdnpoli https://t.co/mDewcl52My RT @ BramptonMasjid: Eid Mubarak! Wishing every one a warm, happy \& full of joy Eid. May the blessings of Allah bring love, 24.05.2020 joy, good health, wealth, \& happiness, and make it a very blessed 23:00 one \& full of peace for everyone. Amin! \#eid \#EidMubarak \#EidUlFitr \#StayHome \#staysafe \#onpoli \#cdnpoli https://t.co/TdETdAqC9d

Table 5. Top 10 - (negative) sentiment twitter postings

\begin{tabular}{|c|c|c|c|}
\hline Sentiment & Screen_name & Created_at & Text \\
\hline-0.9925 & JTaylorSkinner & $\begin{array}{c}24.05 .2020 \\
16: 39\end{array}$ & $\begin{array}{l}\text { Many ppl have gotten better but it's been 3-4 months } \\
\& \text { the virus has already killed more ppl than died in } \\
\text { Vietnam. It's killed more Americans than the Vietnam } \\
\text { War, Gulf War, Afghanistan War, and Iraq War } \\
\text { combined. Americans lived with the Polio epidemic } \\
\text { for } 4 \text { decades! \#StayHome }\end{array}$ \\
\hline-0.9925 & expsurugby & $\begin{array}{c}24.05 .2020 \\
16: 43\end{array}$ & $\begin{array}{l}\text { RT @ JTaylorSkinner: @ sean3kids Many ppl have } \\
\text { gotten better but it's been 3-4 months \& the virus has } \\
\text { already killed more ppl than died in Vietnam. It's killed } \\
\text { more Americans than the Vietnam War, Gulf War, } \\
\text { Afghanistan War, and Iraq War combined. Americans } \\
\text { lived with the Polio epidemic for } 4 \text { decades! } \\
\text { \#StayHome }\end{array}$ \\
\hline-0.9925 & JTaylorSkinner & $\begin{array}{c}24.05 .2020 \\
16: 39\end{array}$ & $\begin{array}{l}\text { RT @ JTaylorSkinner: @ sean3kids Many ppl have } \\
\text { gotten better but it's been 3-4 months \& the virus has } \\
\text { already killed more ppl than died in Vietnam. It's killed } \\
\text { more Americans than the Vietnam War, Gulf War, } \\
\text { Afghanistan War, and Iraq War combined. Americans } \\
\text { lived with the Polio epidemic for } 4 \text { decades! } \\
\text { \#StayHome }\end{array}$ \\
\hline
\end{tabular}




$\begin{array}{ccc}-0.9879 & \text { EURichpixie } & 24.05 .2020 \\ & 22: 14\end{array}$

$-0.9837$

Mambear04

$-0.9792$

GCross24

$-0.9778$

AUn4218473

$-0.9738$

Hayleym1000

$-0.9738$

tenderloinlive
24.05.2020

21:06

24.05.2020

09:04

26.05.2020

11:08

24.05.2020

23:52

20:01
@BorisJohnson the wrong MP, wrong PM, wrong advisor, wrong defence, wrong fight, wrong support, wrong science, wrong communication, wrong way, wrong priority, wrong opinion, wrong plan. \#dominiccummimgs@ @10DowningStreet @Keir_Starmer \#StayHome \#COVID19 \#coronavirus \#COVID @LBC

@HerbieHind85@DylanStrain@adamboultonSKY @BorisJohnson@jeremycorbyn@Conservatives @UKLabour Not sure where you get 4 Labour MPs but they did not travel 260 miles, infected or compile the 'lockdown' rules as Tory Puppet Master Cummings had.. and the vile excuses pushed for his arrogant ignorance of \#StayHome is shameful to the families of those that have died \#COVID-19

So@grantshapps, you're a morally bankrupt twat too. Your pathetic cover-up for your arrogant friend \#dominiccummimgs on \#Marr is shameful. You have betrayed the efforts of us all to \#StayHome \#ProtectTheNHS and \#SaveLives. Resign Shapps. Shameful.

Racist much and The Numbers are Rising not falling MORE people are dying. Your a murderer @ POTUS and should be charged with Crimes against Humanity. Murder Murder Murder \#Resistance \#StayHome \#vote \#VoteBlue2020

RT @tenderloinlive: Fact 9: One in five homeless people suffers from untreated severe mental illness. While about 6 percent of the general population suffers from severe mental illness, 20 to 25 percent of the homeless suffer from severe mental illness, according to government studies. \#StayHome

Fact 9: One in five homeless people suffers from untreated severe mental illness. While about 6 percent of the general population suffers from severe mental illness, 20 to 25 percent of the homeless suffer from severe mental illness, according to government studies. \#StayHome

@ morethanmySLE I'd say \#Darwinism at work but half of these selfish assholes will infect an innocent person who will die. If they can be contact traced they should be charged with murder. \#COVIDIOTS \#TrumpDeathToll100K \#TrumpGolfsYouDie \#StayHome \#WearAMask

"Sentiment analysis is a field of study that analyzes people's ideas, feelings, evaluations and attitudes from written language. It is one of the most active research areas in natural language processing. Sentiment analysis and data mining are intensively studied in the fields of web mining and text analysis" (Akaichi, 2014). "Because sentiment analysis is important for 
business and society, it finds application in disciplines such as management sciences and social sciences as well as computer science. The workspace of emotion analysis is expanding with different aspects of social media such as comments, forum discussions, blogs, microblogs, Twitter and social networks, and the importance of sentiment analysis is increasing" (Liu, 2012). As shown in the figure 4 sentiment analysis result screen includes positive, negative or neutral analysis of tweets. The positive and negative states of tweets, both numerically and by percentage, are shown.

\section{Future Directions}

Our paper of the usage of Twitter to textual and sentimental analysis on public health tweets focused on producing statistics that correlate with the general public interest and sentimental situation. Twitter carries many different types of statistics of value to public health-related social networking analyses on many specific topics. The next step is to don't forget what new statistics may be learned by studying Twitter, probably assisting new health communication hypotheses. We plan to don't forget more particular applications to learn new matters from Twitter.

The findings and results that emerged within the scope of our study reveal that the use of social media increased especially in issues related to public health in times of crisis. The global dimension of hazards and outbreaks has shown the importance of citizens' access to accurate and up-to-date information. As new technologies enable the public to obtain crisis facts faster, the converting nature and developing the usage of such new technology may be a guide for future studies. Overall, more research is needed on the use of twitter for global crises and pandemic activities. For instance, although Twitter microblogging tool was not designed to react instantly and to be a crisis management tool, it seems that it plays this role in the Coronavirus crisis.

\section{Discussion}

It should be stated that if social media is used to systematically reveal Coronavirus outbreak within the future, there are capacity problems that may additionally want to be taken into consideration so that it will keep the reliability of Twitter used. For instance, the public reputation of those techniques could Coronavirus outbreak behaviour and therefore motive disinformation. It is not difficult to assume a state of affairs in which Twitter users may additionally falsify outbreak-related tweets on the manner to garner extra hobby from public health officials and receive greater resources which include death toll. However, as mentioned by Petróczi and Haugen (2012, pp.514-516), "such disinformation can be counterbalanced with the useful resource of moreover direct information motivates humans might also 
moreover have for distorting the truth, and those insights can moreover allow researchers to perceive Twitter posts that are probable to be".

A collection of recurring "hot subjects", which suggests viable topics for similarly research, has emerged. However, this take a look at has several limitations: because of the constraints of the software program used facts series was confined in time and amount; a quantitative, instead of qualitative, evaluation of the sentiment conveyed through the tweets couldn't be obtained, due to still inadequate equipment for semantic analysis for some medical phrases and foreign tweets.

\section{Conclusion}

What do we need to do when looking for accurate information in the face of the global crisis caused by the pandemic on social media platforms? It is important to follow the correct calculations for the correct information in the flow. Instead of "expert voices" that are far from scientific knowledge circulating in the media and the new media ecosystem, it is necessary to follow accounts that speak with scientific references, accounts of global and national institutions producing content based on the principle of public interest. Because it is necessary to act with the awareness of the responsibility of producing accurate and qualified content about the pandemic while perceiving and sharing every content. Otherwise, we will contribute to information loading and information pollution. In global crises, and especially in events that affect the whole world, it is necessary to think once again about the quality of each share, who we mention, what we share.

Public health cases are openly discussed and informed on Twitter, with distinct targets and motivations, ranging from scientific hobby to guidelines for everyday life. Tweets on Coronavirus outbreak are common than those on several other health conditions, but they depict the most critical and habitual subject matters for Covid-19 patients, from diagnosis to comorbidities to prevention of complications. Although we hypothesized that outbreak would be an ordinary theme, thinking about the volume to which coronavirus is being "misinformed" by way of social media, we discovered that that is a not unusual topic. We trust that social media could improve the overall expertise of public health-based clarification of the potentially harmful outcomes of Covid-19.

The effect and reliability of social media on disaster recovery may be challenged by carrying out a content review focused solely on the semantic analysis of tweets shared on Twitter with phrases and frequencies used. Social networking and Twitter content are recognized worldwide as effective tools for public health messages for use in disease monitoring and disaster management. Twitter is not only an instant social network but also an exceedingly significant news source. Understanding, then, propagation of 
tweeting news from the authorities is very important essential for a variety of reasons, such as information, crisis and management of public health policies.

\section{References:}

1. Adelaja, I., Sayma, M., Walton, H., McLachlan, G., de Boisanger, J., Bartlett-Pestell, S., \& Fung. (2020). CYA comprehensive hospital agile preparedness (CHAPs) tool for pandemic preparedness, based on the COVID-19 experience. Future Healthcare Journal. 2020;7:1-4. doi:https://doi.org/10.7861/fhj.2020-0030

2. Akaichi, J. (2014). Sentiment Classification at the Time of the Tunisian Uprising: Machine Learning Techniques Applied to a New Corpus for Arabic Language. 2014 European Network Intelligence Conference, Wroclaw, 2014; 38-45. doi: https://10.1109/ENIC.2014.35

3. Bjørkdahl, K. \& Carlsen, B. (2019). Introduction: Pandemics, Publics, and Politics-Staging Responses to Public Health Crises. In Pandemics, Publics, and Politics, Palgrave Pivot, Singapore,1-9.

4. Bucher, T. (2017). The algorithmic imaginary: exploring the ordinary effects of Facebook algorithms. Information, Communication \& Society. 20, 30-44. doi:https://doi.org/10.1080/1369118X.2016.1154086

5. Chen Z.L., Zhang Q., Lu Y., Guo Z.M., Zhang X., Zhang W.J., Guo C., Liao C.H., Li Q.L.,Han X.H.., Lu J.H. (2020). Distribution of the COVID-19 epidemic and correlation with population emigration from Wuhan, China. Chinese Medical Journal. 1-18. doi:https://doi.org/10.1097/CM9.0000000000000782

6. Conti, P. (2020). Sentiment analysis Interpret if a text has an overall positive or negative connotation. [internet].[cited 2020 June 8] Available from

http://help.workbenchdata.com/en/articles/2322994-sentimentanalysis

7. Dijk, V.J.A.G.M. (2006). The Network Society: Social Aspects of New Media. 2006. London:Sage Publications.

Hutto, C.J. \& Gilbert, E.E. (2014). VADER: A Parsimonious Rulebased Model for Sentiment Analysis of Social Media Text. Eighth International Conference on Weblogs and Social Media (ICWSM-14). Ann Arbor, MI, June 2014.

8. Jones, R.C. (2020). Can Zuckerberg stop Facebook's coronavirus conspiracies? [internet].[cited 2020 June 6]. Available from https://www.bbc.com/news/technology-51739846 
9. Karabulut, Y.E. \& Küçüksille E.U. (2018). Twitter Professional Monitoring and Analytics Tool. Journal of Technical Sciences.8,1724.

10. Lachlan, K.A., Spence, P.R., \& Lin, X. (2014). Expressions of risk awareness and concern through Twitter: On the utility of using the medium as an indication of audience needs. Computers in Human Behavior, 35, 554-559. doi:https://doi.org/10.1016/j.chb.2014.02.029.

11. Liu, B. (2012). Sentiment analysis and opinion mining. Synthesis lectures on human language technologies, 5, 1-167.

12. Love, B., Himelboim, I., Holton, A., \& Stewart, K. (2013). Twitter as a source of vaccination information: content drivers and what they are saying. American Journal of Infection Control, 41(6), 568-570. doi: http://dx.doi.org/10.1016/j.ajic.2012.10.016

13. McGregor, S.C. (2019). Social media as public opinion: How journalists use social media to represent public opinion. Journalism, 20(8), 1070-1086.

doi: https://doi.org/10.1177/1464884919845458.

14. Nie, J.B. (2020). In the Shadow of Biological Warfare: Conspiracy Theories on the Origins of COVID-19 and Enhancing Global Governance of Biosafety as a Matter of Urgency. Bioethical Inquiry, 1-8. doi: https://doi.org/10.1007/s11673-020-10025-8.

15. Petróczi A. \& Haugen, K. (2012). The Doping Self-Reporting Game: The Paradox of a 'false-Telling' Mechanism and Its Potential Research and Policy Implications. Sport Management Review, 15, 513-517. doi: https://10.1016/j.smr.2012.04.002

16. Stewart, A. (2020). What's trending during coronavirus pandemic? A definitive guide to the most used hashtags. Crisis. [internet].[cited 2020 June 10].

Available from https://www.thenational.ae/arts-culture/what-strending-during-coronavirus-pandemic-a-definitive-guide-to-themost-used-hashtags-1.996208

17. Szmuda, T., Özdemir, C., Ali, S., Singh, A., Syed, M.T., Słoniewski, P. (2020). Readability of Online Patient Education Material for the Novel Coronavirus Disease (COVID-19): A Cross-sectional Health Literacy Study. Public Health. 2020;185:21-25. doi: https://doi.org/10.1016/j.puhe.2020.05.041

18. Tang, S., Chow, A. Y., Breen, L. J., \& Prigerson, H. G. (2020). Can grief be a mental disorder? An online survey on public opinion in mainland China. Death Studies, 44(3), 152-159. doi: https://doi.org/10.1080/07481187.2018.1527415 
19. The United Nations Department of Global Communications (DGC). (2020). UN tackles 'infodemic' of misinformation and cybercrime in COVID-19 crisis [internet].[cited 2020 June 8]. Available from https://www.un.org/en/un-coronavirus-communications-team/untackling-\%E2\%80\%98infodemic\%E2\%80\%99-misinformation-andcybercrime-covid-19

20. Tufan, Z.K. \& Kayaaslan, B. (2020). Crushing the curve, the role of national and international institutions and policymakers in COVID-19 pandemic. Turkish Journal of Medical Sciences, TUBITAK. 495-508. doi: https://10.3906/sag-2004-167.

21. WHO. (2020a). Pneumonia of Unknown Cause-China. [internet]. [cited 2020 June 8].

Available from https://www.who.int/csr/don/05-january-2020pneumonia-of-unkown-cause-china/en/

22. WHO. (2020b). Coronavirus Disease 2019 (COVID-19) Situation Report-46. [internet]. [cited 2020 June 8]. Available from https://www.who.int/docs/default-source/coronaviruse/situationreports/20200306-sitrep-46-covid-9.pdf?sfvrsn=96b04adf_2

23. WHO. (2020c). Rolling Updates on Coronavirus Disease (COVID19). [internet].[cited 2020 June 8]. 2020c. Available from https://www.who.int/emergencies/diseases/novel-coronavirus2019/events-as-they-appen

24. Yoon, S., Elhadad, N., \& Bakken, S. (2013). A practical approach for content mining of tweets. American Journal of Preventive Medicine, 45(1), 122-129. ISSN 0749-3797

doi: https://doi.org/10.1016/j.amepre.2013.02.025. 